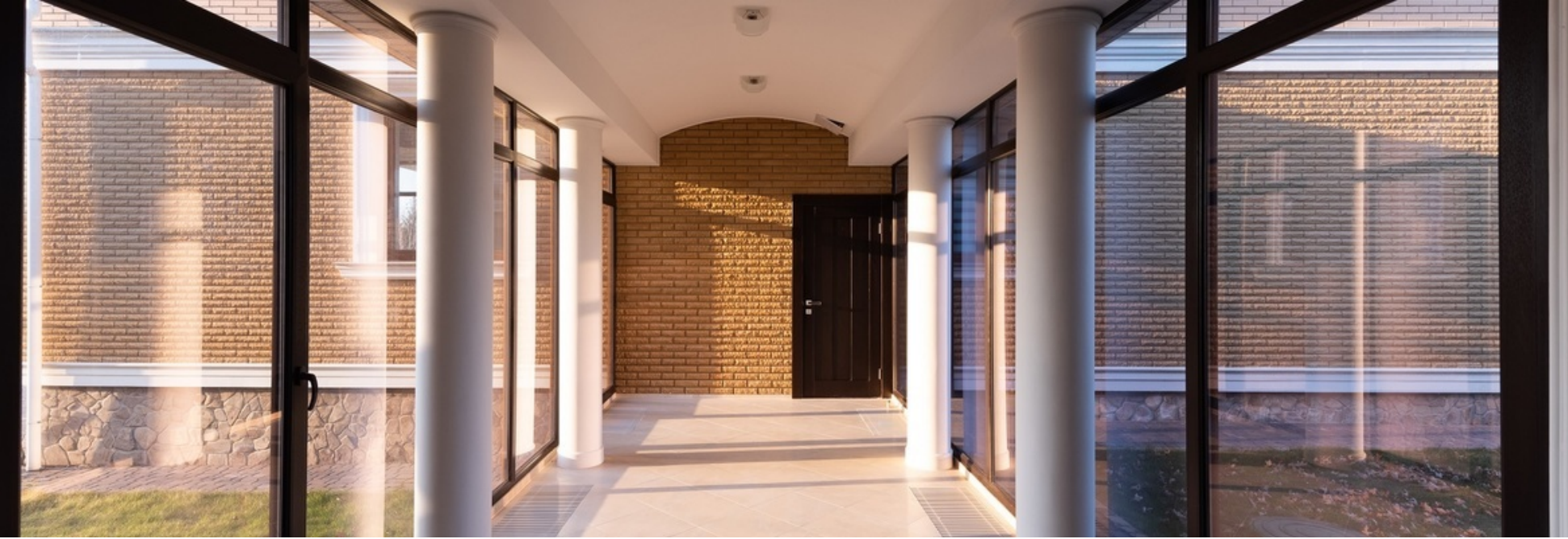

\title{
Assessment of primary Health Care Facilities in Kosovo using Space Syntax Analysis
}

Authors:

Submitted:

Published:

Volume:

Issue:

Affiliation:

Languages:

Keywords:

Categories:

DOI:
Bardha Meka, Vlora Navakazi, Flaka Xërxa Beqiri 19. June 2021

5. July 2021

8

3

University of Prishtina, Kosovo

English

Primary Health Care, Space syntax, POE, public spaces Visual Arts, Architecture and Design 10.17160/josha.8.3.764

Abstract:

The design of our built environment affects our health and well-being and can have a long-term implication for quality of life. The quality of architecture and design can play a fundamental role in positively or negatively affecting patients, family members and operators generating feelings and perceptions of safety, comfort, privacy and psychological well-being . Primary health care facilities in Kosovo which recently underwent renovation are comparable to the average of other European countries regarding the size and the structure, but still far from reaching highest standards with regards to well-developed primary care systems in the world. This study aims to investigate four different floor plan typologies of Main Family Medicine Centres (MFMC) In Kosovo after they have been renovated, based on space syntax analysis complemented by direct observations and questionnaires, concerning the humanization of primary healthcare facilities with regard to user's needs, including the criteria of accessibility, wayfinding, privacy, visibility, proximity, safety and environmental comfort. Space syntax analyses and complementary method of Post Occupancy Evaluation (POE) applied in this study, helped to understand weaknesses and spatial potentialities offered bv a certain tvpe of lavout.

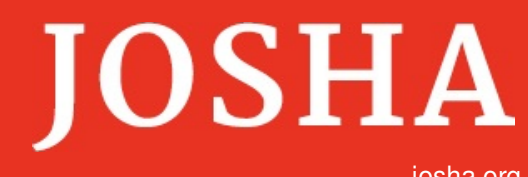

josha.org
Journal of Science, Humanities and Arts

JOSHA is a service that helps scholars, researchers, and students discover, use, and build upon a wide range of content 


\title{
Assessment of primary Health Care Facilities in Kosovo using Space Syntax Analysis
}

\author{
1 Bardha MEKA, 2* VLORA NAVAKAZI, 3 FLAKA XERXA-BEQIRI \\ 1,2, 3 Faculty of Architecture, University of Prishtina "Hasan Prishtina", St Ark. Karl Gega, No 1, \\ 10000 Prishtina, Republic of Kosovo \\ e-mail: bardha.meka@uni-pr.edu, ${ }^{*}$ corresponding authorvlora.navakazi@uni-pr.edu, \\ flaka.xerxa@uni-pr.edu
}

\begin{abstract}
The design of our built environment affects our health and well-being and can have a long-term implication for quality of life. ${ }^{1}$ The quality of architecture and design can play a fundamental role in positively or negatively affecting patients, family members and operators generating feelings and perceptions of safety, comfort, privacy and psychological well-being ${ }^{2}$. Primary health care facilities in Kosovo which recently underwent renovation are comparable to the average of other European countries regarding the size and the structure ${ }^{3}$, but still far from reaching highest standards with regards to well-developed primary care systems in the world. This study aims to investigate four different floor plan typologies of Main Family Medicine Centres (MFMC) In Kosovo after they have been renovated, based on space syntax analysis complemented by direct observations and questionnaires, concerning the humanization of primary healthcare facilities with regard to user's needs, including the criteria of accessibility, wayfinding, privacy, visibility, proximity, safety and environmental comfort. Space syntax analyses and complementary method of Post Occupancy Evaluation (POE) applied in this study, helped to understand weaknesses and spatial potentialities offered by a certain type of layout.
\end{abstract}

Key words: Primary Health Care, Space syntax, POE, public spaces

\footnotetext{
${ }^{1}$ Steemers K. (2015), “Architecture for well-being and health”, Daylight \& Architecture, Spring 2015, Issue 23, pp 6-27.

${ }^{2}$ Ulrich R. (2001), "Effects of healthcare environmental design on medical outcomes", in: Dilani A. (ed.), Design and Health - The therapeutic benefits of design, Stockholm: AB Svensk Byggtjanst

${ }^{3}$ WHO (2019), Primary health care in Kosova: rapid assessment
} 


\section{Introduction} Background

Primary Health Care (PHC) is usually associated with the declaration of the 1978 International Conference in Alma Ata, Kazakhstan (known as the "Alma Ata Declaration"). Alma-Ata put health equity on the international political agenda for the first time, and PHC became a core concept of the World Health Organization's (WHO) goal of Health for all. ${ }^{4}$ The meaning of primary health care (PHC) has evolved over time. Primary health care is a whole-of-society approach to health and well-being centered on the needs and preferences of individuals, families and communities. ${ }^{5}$

The design of our built environment affects our health and well-being and can have a long term implication for quality of life. ${ }^{6}$ The quality of architecture and design can play a fundamental role in positively or negatively affecting patients, family members and operators through those elements characterizing buildings and spaces that generate feelings and perceptions of safety, comfort, privacy and psychological well-being?

PHC in Kosovo is organized through a network of family medicine centres owned by local municipalities. Kosovo has 430 family medicine centres. Each municipality has a network of family medicine centres - one main family medicine centre and several affiliated centres (with family doctors and nurses) or medical posts (only nurses). ${ }^{8}$ In alignment with the regulatory framework, PHC in Kosovo provides quality and safe health services, based on the principles of family medicine and led by the needs and requirements of individuals, families and communities with the final aim at promoting, preserving and improving health for all. ${ }^{9}$

According to WHO, "in Kosovo, fewer people than in other European countries are satisfied with their visits to PHC and studies indicate that patients' expectations for PHC services in Kosovo have not been met". ${ }^{10}$ Primary health care facilities in Kosovo which recently underwent renovation "are comparable to the average of other European countries regarding the size and the structure, but still far from reaching highest standards with regards to well-

\footnotetext{
${ }^{4}$ Litsios S. (2015): "On the Origin of Primary Health Care”. Health For All: The Journey of Universal Health Coverage. Ed by: Medcalf A, Bhattacharya S, Momen H, et al., Hyderabad (IN): Orient Blackswan; Chapter 1. ${ }^{5}$ WHO and UNICEF. (2018). A vision for primary health care in the 21 st century: towards universal health coverage and the Sustainable Development Goals. World Health Organization.

${ }^{6}$ Steemers K. (2015), “Architecture for well-being and health", Daylight \& Architecture, Spring 2015, Issue 23, pp 6-27.

${ }^{7}$ Ulrich R. (2001), "Effects of healthcare environmental design on medical outcomes", Design and Health - The therapeutic benefits of design, ed by: Dilani A. (ed.), Stockholm: AB Svensk Byggtjanst

${ }^{8}$ WHO (2019), Primary health care in Kosova: rapid assessment.

9 WHO (2019), Primary health care in Kosova: rapid assessment.

${ }^{10}$ WHO and UNICEF. (2018). A vision for primary health care in the 21st century: towards universal health coverage and the Sustainable Development Goals. World Health Organization.
} 
developed primary care systems in the world" ${ }^{11}$ There were considered attempts to improve the primary healthcare facilities in Kosovo. To some extent there were implemented policy priorities which reflect people's need and preferences. Architecture of existing PHCs in Kosovo, mainly built during 60s to 80s based on "technocratic approach", the era of functionally driven architecture, as a consequence, very often didn't consider user's needs.

The focus of this research was directed at identifying critical design issues in four main family medicine centers in Kosovo after they have been renovated and how these issues were addressed regarding their impact in the quality and efficiency of primary care in terms of humanization.

The aim was to explore different typologies in terms of meeting the criteria for design of PHC. Responses to quality design, concerning the humanization of PHC with regard to user's needs, include the criteria for observation/evaluation such as: accessibility, wayfinding, privacy, visibility, proximity, safety and security, which were investigated through configurational analyses, based on space syntax methodology, complemented by direct observations and questionnaires.

\section{Materials and Methods}

Four renovated Main Family Medicine Centres (MFMC) in Kosovo selected to be analysed are: MFMC in Prishtina, Prizren, Obiliq and Fushe Kosovë.
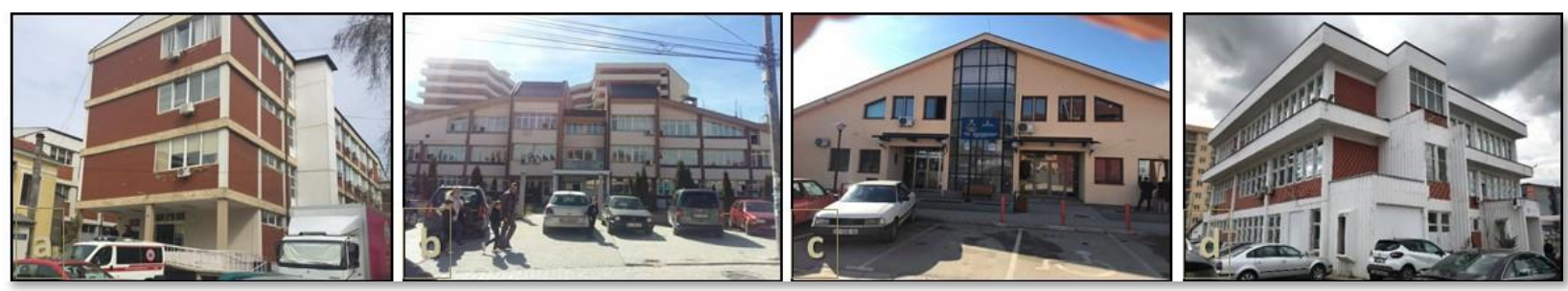

Figure 1. Four case studies of Four Main Family Medicine Centres (MFMC): a) MFMC in Municipality of Prishtina; b) MFMC in Municipality of Prizren; c) MFMC in Municipality of Obiliq; d) MFMC in Municipality of Fushë Kosovë

Initially, through desk study and site visits, certain MFMC typologies, regarding basis form and characteristics of internal spatial organization were identified: F-shaped typology with two face corridors (a), ring typology with two wings wrapped round courtyards with double corridor (b), mixed of I and ring type with core and two-faced corridor (c), and ring type with core (d).

\footnotetext{
${ }^{11}$ Ibid 10
} 

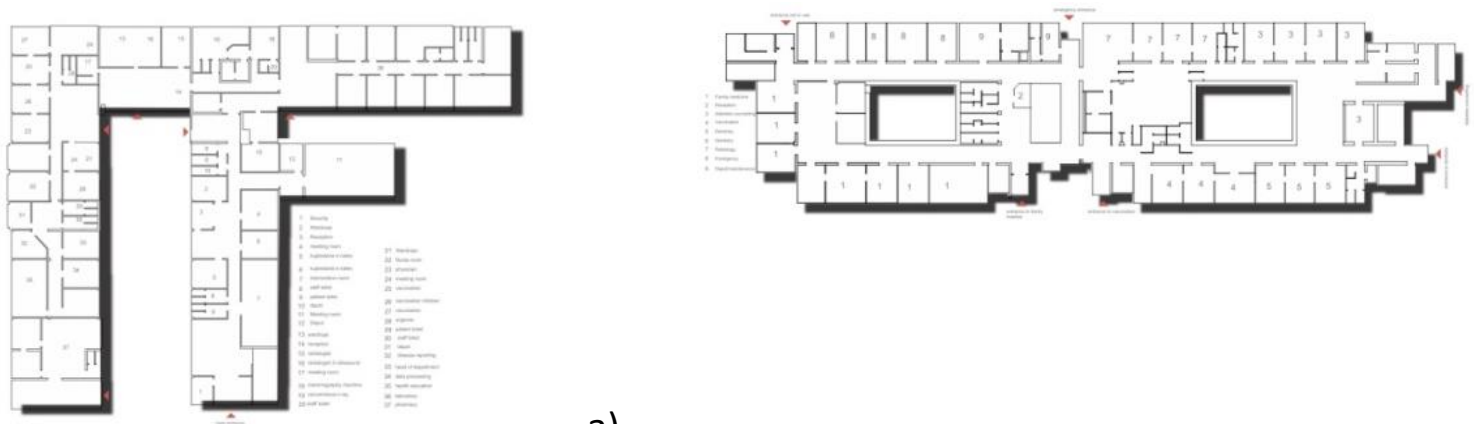

b)

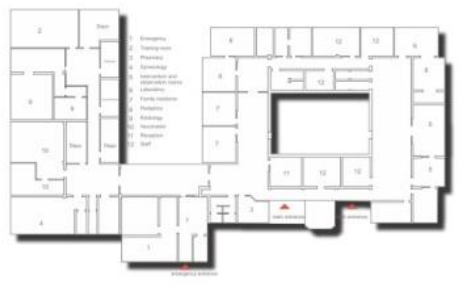

c)

a)

d)

Figure 2 The layout of the ground floor of MFMC:

a) Prishtinë, b) Prizren, c) Obiliq, d) Fushë Kosovë (Source: Author)

Some of the criteria for PHC design based on humanization principles were initially identified from the literature. Accessibility, proximity, wayfinding, safety, security and privacy are recommended as important factors in better understanding of patient-focused architecture. ${ }^{12}$ Regarding functional design issues, HBN (UK) also recommend above mentioned criteria as important. In addition, they specify attributes of public zones such as main entrance, reception desk and waiting area to be "open and welcoming, visible from outside the building and to aid building legibility." They also paid attention to inter-visibility between these components of public zone.

Space syntax methodology was used to analyse the selected layouts from a configuration point of view. Space syntax is a theory and method as developed by Bill Hillier and his colleagues at University College London (UCL). It has proceeded in two ways. One was creating and developing a theory, with the idea that spatial layout generates material preconditions for social life as understood by movement, encounter, avoidance etc., the other was constructing a method to analyse layouts according to that theory, which is more mathematical and technological, ultimately leading to the development of various computerized software

\footnotetext{
${ }^{12}$ Purves G. (2002), Healthy Living Centres a guide to primary health care design, pp. 42
} 
packages $^{13}$. These analyses are complemented by qualitative approach such as interviews, questionnaires and observational studies.

The evaluation of the criteria derived from literature was performed through configuration analysis, VGA method, which provides data on the behaviour of syntactic parameters such as Integration, Connectivity and Intelligibility. Using visibility graph analyses (VGA) enables identification of design deficiencies and potential of analysed areas with regard to accessibility, circulation, way-finding, privacy and visibility. While, Isovist was used to visualize the view from a particular point in the built environment. Visibility graph is the graph of mutually visible locations in a spatial layout. ${ }^{14}$ Turner et. al. (2001) has constructed an undirected graph connecting all the inter-visible points in a human-scale grid, where visual relationships between different nodes in the system can be calculated using different local and global measures in Depthmap. ${ }^{15}$ An isovist, or viewshed, first introduced by Benedikt (1979), is the area in a spatial environment directly visible from a location within the space. ${ }^{16}$ Integration represents the average distance of one space from all other spaces in a layout and it indicates how close the origin space is to all other spaces. ${ }^{17}$ The $10 \%$ of most integrated values $(10 \%)$ in the system is called integration core. Connectivity is a syntactic property that measures the number of spaces immediately connecting a space of origin. ${ }^{18}$ Intelligibility is the variable for the entire layout and it is measured by the correlation coefficient between connectivity and integration of all the spaces in that layout. ${ }^{19}$ It helps identify how easy it is for one in a local position to comprehend the global structure. ${ }^{20}$

\section{Results and discussion}

The ground floor plans of all cases have been represented by VGA map to show their visual integration and connectivity values (Fig. 2). Hierarchy of routes and integration core was identified. The lightest locations are the most visually integrated, through to darkest for the least.

\footnotetext{
${ }^{13}$ Haq S., (2012). Space Syntax in Healthcare Facilities Research: A Review

14 Turner, A., Doxa, M., O’Sullivan, D., and Penn, A. (2001) From Isovists to Visibility Graphs: A Methodology for the Analysis of Architectural Space. Environment and Planning B: vol 28, 103-121. pp.108-109

${ }^{15}$ Al Sayed, K. (2018), Space Syntax Methodology, pp. 29

${ }^{16}$ Ibid 16

${ }^{17}$ Haq S., (2018), Where We Walk Is What We See: Foundational Concepts and Analytical Techniques of Space Syntax

${ }^{18}$ Hillier, B. \& Hanson, J. (1984), The Social Logic of Space, Cambridge University Press: Cambridge. pp.103

${ }^{19}$ Ibid 18

${ }^{20}$ Al Sayed, K. (2018), Space Syntax Methodology, pp. 29
} 

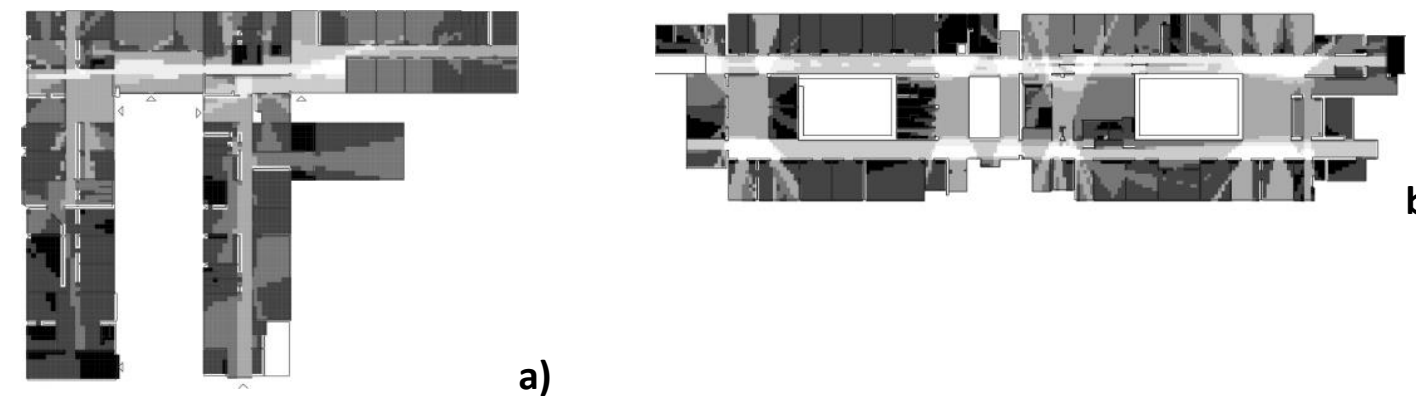

b)

a)

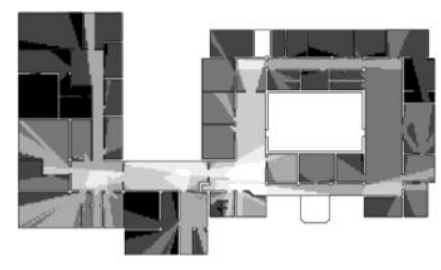

c)

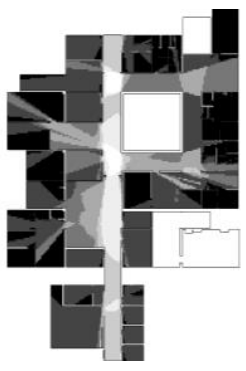

d)

Figure 3 VGA analyses of MFMC (below), most integrated areas (lightest), most segregated areas (darkest)

The highest mean values of connectivity and integration (Table 2) were found in the case $\boldsymbol{d}$ (Conn_1072; Int_Rn 6.1), while the lowest was found in the case $\boldsymbol{a}$ (Conn_375; Int_Rn 2.8). This means that high value of integration leads the plan of the case (d) to be more visible, perceptible, and readable. In the case (a), entrance and reception were segregated with regard to the accessibility core, while in the case (b), (c) and (d) were in close proximity to the more integrated areas of the system. The value of the intelligibility, the correlation between the connectivity and global integration, is higher in case $\boldsymbol{b}\left(R^{2}=0.83\right)$ and $\boldsymbol{d}(0.83)$, while lower values of intelligibility were found in case $\boldsymbol{a}\left(R^{2}=0.22\right)$ and case $c\left(R^{2}=0.34\right)$. This shows that wayfinding is more supported on the cases of "ring" typologies ( $b$ and $d$ ) in comparison to other types.

Table 2 Attribute summaries (VGA) for each Main Family Care Centre

\begin{tabular}{|l|l|l|l|l|l|l|l|l|}
\hline \multirow{2}{*}{ Facility Name } & \multicolumn{3}{|l|}{ Connectivity } & \multicolumn{3}{l|}{ Visual Integration } & Intelligibility \\
\cline { 2 - 9 } & Min. & Aver. & Max. & Min. & Aver. & Max. & \\
\hline a & Prishtina & 3 & 117.3 & 375 & 1.5 & 2.8 & 5.1 & $\mathrm{R}^{2}=0.22$ \\
\hline b & Prizren & 8 & 446.3 & 1502 & 2.2 & 5.9 & 9.5 & $\mathrm{R}^{2}=0.83$ \\
\hline c & Obiliq & 24 & 810 & 2538 & 2.2 & 4.1 & 7.4 & $\mathrm{R}^{2}=0.34$ \\
\hline d & Fushë Kosovë & 36 & 1072.3 & 3978 & 3 & 6.1 & 11.6 & $\mathrm{R}^{2}=0.83$ \\
\hline
\end{tabular}


Public areas were investigated also with isovist analysis (Figure 4, Figure 5). Specific isovists within each plan are used to examine visibility from specified components of public zone (main entrance, reception desk and security).

Structure $\boldsymbol{b}$ has provided good solutions in terms of visibility from both the main entrance and the desk reception, which is the opposite of structure $\boldsymbol{c}$, which has no inter- visibility either between the main entrance and the desk reception nor with other parts.

Isovist analyses show that in case $\boldsymbol{a}$ there was no inter - visibility from the main entrance to reception desk. There was no visibility from main entrance to stairs and elevator and only a part of waiting room was visible. Reception desk lacks the view to stairs and elevator, and the same situation appeared for security room in relation to reception and waiting room. In case $\boldsymbol{b}$, reception desk was visible from main entrance. From this point it was possible to see the stairs, whereas there was sufficient visibility from reception desk to both entrances. In case $c$ isovist area from the main entrance did not include the reception desk and waiting room and vice versa. The same results were found in case $\boldsymbol{d}$. In conclusion, only structure $\boldsymbol{b}$ has provided good solutions in terms of visibility regarding both the main entrance and the reception desk, which is the opposite for structure $\boldsymbol{a}, \boldsymbol{c}$ and $\boldsymbol{d}$, which had no inter-visibility, either between the main entrance and the reception desk, nor with other parts.
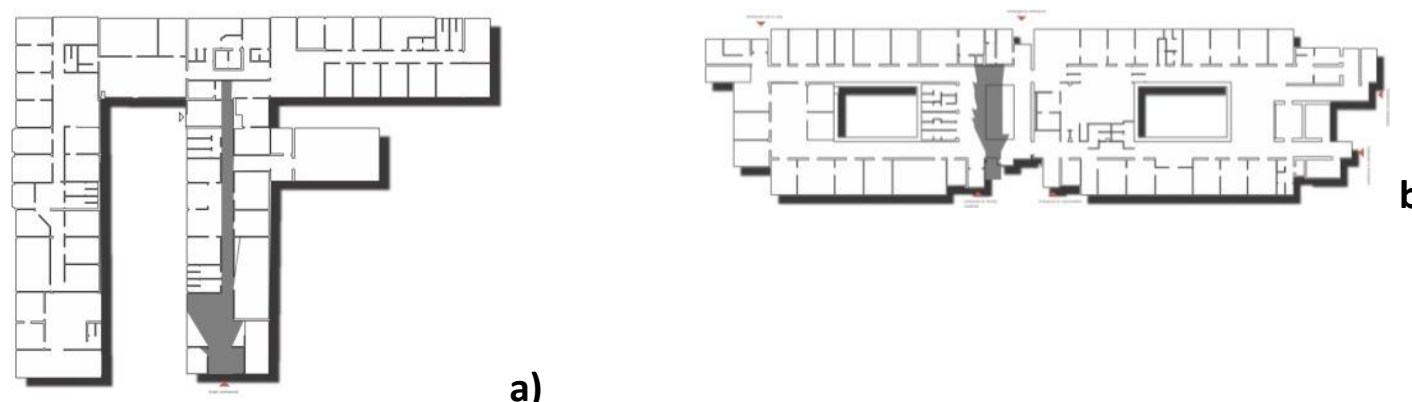

b)

a)

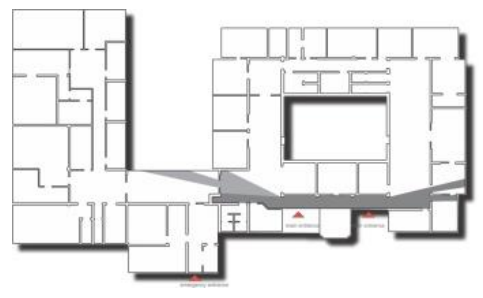

c)

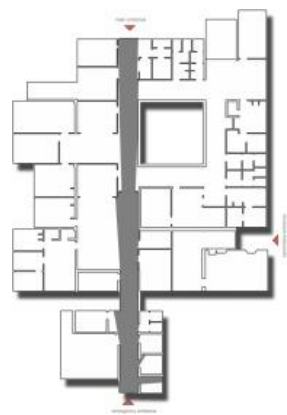

d)

Figure 4 Isovist maps analyses from main entrance:

Prishtinë (a), Prizren (b), Obiliq (c), Fushë Kosovë (d) 
Regarding the position and the numbers of the entrances to the structure, the study found that in addition to main entrances, there are several other entrances (case $\boldsymbol{a}$ and $\boldsymbol{b}$ ), dedicated to spaces with different functions. Their use is available from the courtyard, although there is a connection through the building, but quite distant. According to HBN (UK), "ideally, only one public entrance to the building should be provided, as this avoids confusion and aids security".
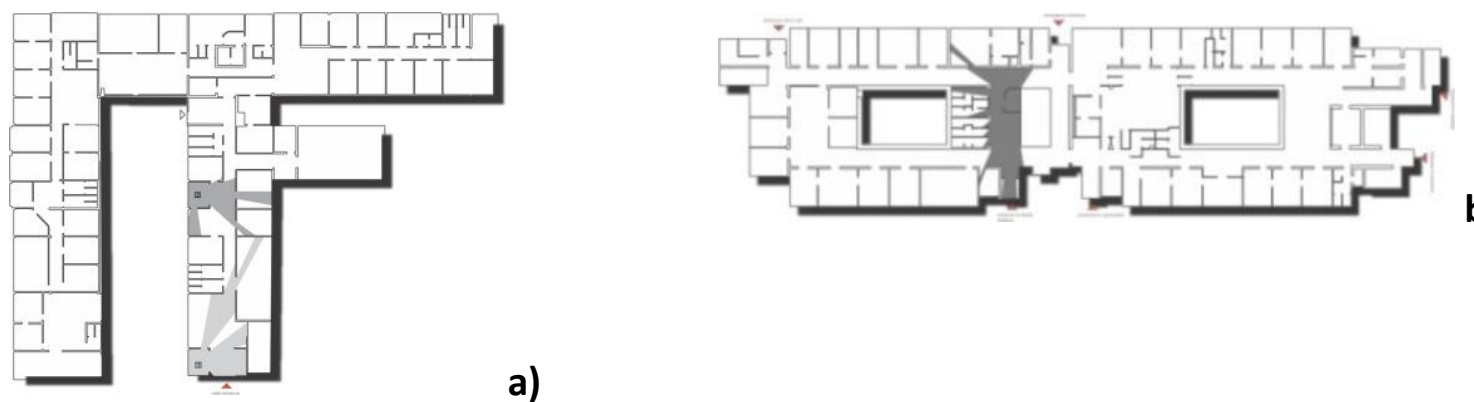

b)

a)
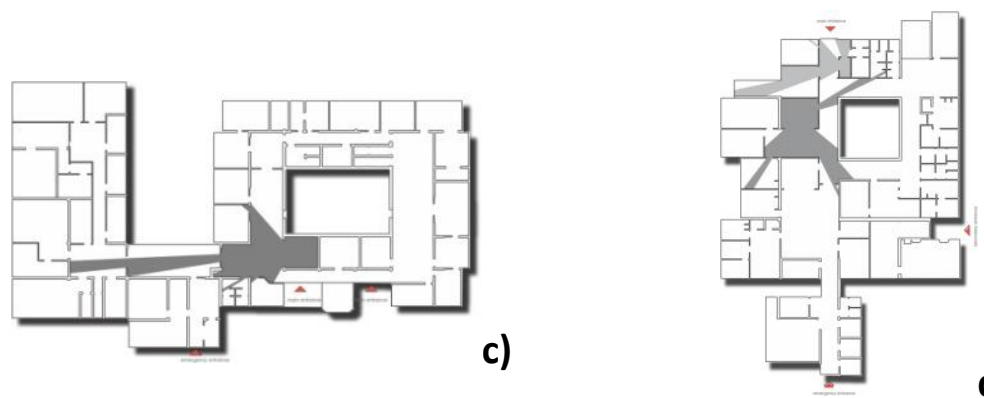

Figure 5 Isovist maps analyses from security and reception:

Prishtinë (a), Prizren (b), Obiliq (c), Fushë Kosovë (d)

Another data have been obtained from the questionnaire survey. Questions applied to users were related to accessibility, way finding, privacy, environmental comfort etc. Most respondents from cases $\boldsymbol{a}(55 \%)$ and $\boldsymbol{b}(50 \%)$ encountered difficulties in identifying the main entrance. This may be due to the large number of entrances to the facility. 


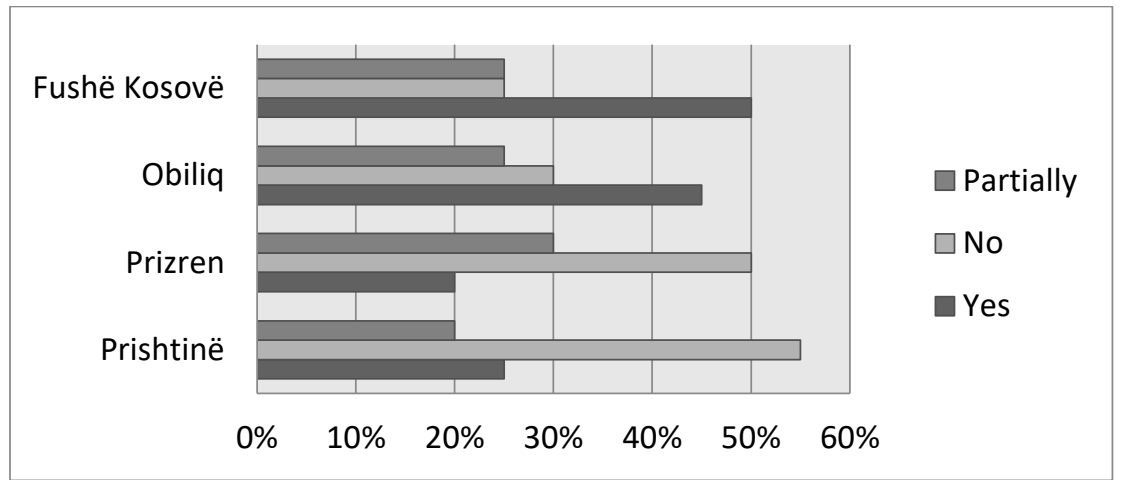

Figure 6 Question for patients and visitors regarding visibility of main entrance

Majority of respondents (65\%) from the case $\boldsymbol{a}$ have encountered difficulties in finding the appropriate destination while walking inside the building, which means that this structure offers limited ability for navigation. While, cases $\boldsymbol{b}$ and $\boldsymbol{d}$ show better results regarding this issue.

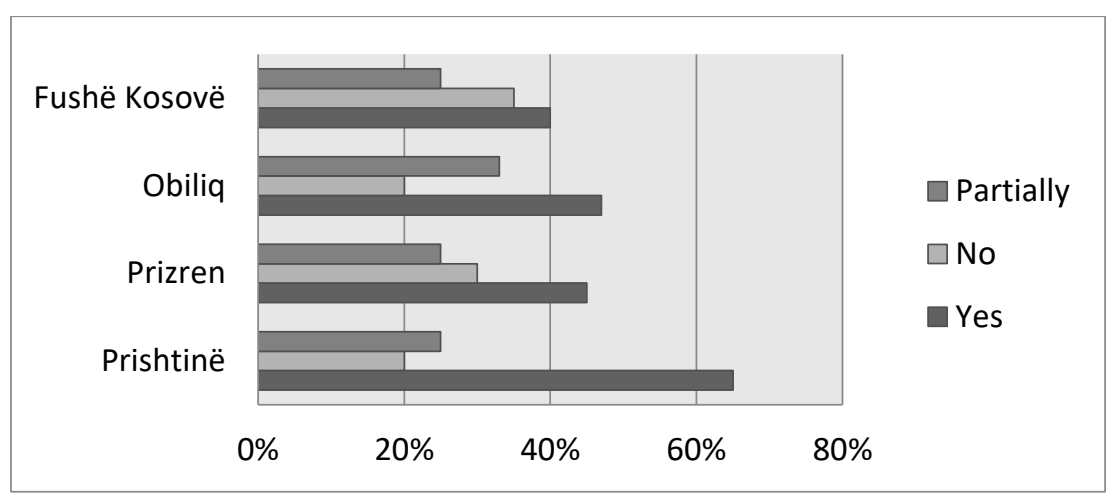

Figure 7 Question for patients and visitors regarding the orientation

The largest percentage of respondents from all cases stated that insufficient reception visibility and insufficient visibility from the reception to the stairs and elevators causes difficulties in finding the destination. These data match with the results from isovist analyses regarding this topic for cases $\boldsymbol{a}$ and $\boldsymbol{c}$. 


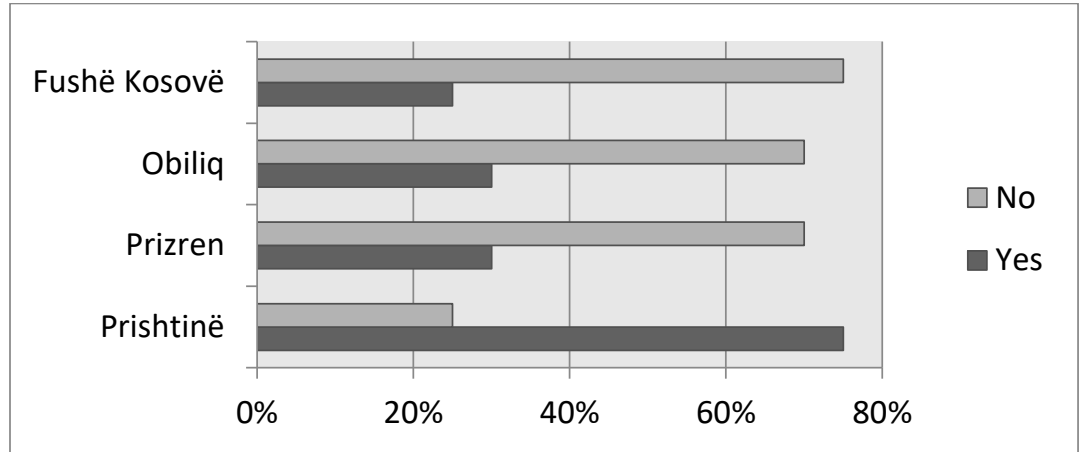

Figure 8 Question for patients and visitors regarding wayfinding

Of all the cases, the case $\boldsymbol{a}$ was presented with the largest number of respondents (79\%) who asked the staff to find the respective destination. This could be due to the F-shaped layout, which has dictated inappropriate distribution of services and the appearance of many entrances from the courtyard.

\section{Conclusions}

According to WHO, PHC in Kosovo are comparable to the average of other European countries regarding the size and the structure. But built in the $60-80$ s, little emphasis has been given to psychological and social needs.

The analyses carried out, both in terms of configuration through space syntax analyses and complemented by Post Occupancy Evaluation (POE), in four recently renovated MFMCs, show their potential and weaknesses offered by a certain type of layout. Study show that wayfinding is more supported on the cases of "ring" typologies (cases $\boldsymbol{b}$ and $\boldsymbol{d}$ ). While this typology for case $\boldsymbol{b}$ provided good solutions in terms of inter-visibility of public premises, was not achieved in case $\boldsymbol{d}$ (isovist). This means that the "ring" typology offers better spatial potentiality, but in case of improper arrangement of public components fails to fulfil the required standards. In addition, even in cases of meeting these criteria, neglecting the physical environment able to support patient psychological and social needs, public spaces remain non-welcoming, as for example in case $\boldsymbol{b}$. Among the explored layout typologies, F-shaped typology appeared with the greatest weaknesses (case $\boldsymbol{a}$ ). Low intelligibility values indicate that the layout is less perceptible and less readable. Regarding public premises, this structure has provided low standards in terms of visibility. These findings were also supported by questionnaires and direct observations, which indicate the need of patients for guidance by asking staff for orientation. 
Architecture of existing primary healthcare in Kosovo built with technocratic approach appears to be challenging to implement highest standards and have shown to be difficult to upgrade and renovate. Although renovated, poorly interior design, lacked open plan, airy spaces and sources of daylight, suffering welcoming and supportive healthcare environments.

\section{References}

Al Sayed, K. (2018), Space Syntax Methodology, pp. 29

Haq S., (2018), Where We Walk Is What We See: Foundational Concepts and Analytical Techniques of Space Syntax

Haq S., (2012). Space Syntax in Healthcare Facilities Research: A Review

Hillier, B. \& Hanson, J. (1984), The Social Logic of Space, Cambridge University Press: Cambridge. pp.103

Litsios S. (2015): "On the Origin of Primary Health Care". Health For All: The Journey of Universal Health Coverage. Ed by: Medcalf A, Bhattacharya S, Momen H, et al., Hyderabad (IN): Orient Blackswan; Chapter 1

Purves G. (2002), Healthy Living Centres a guide to primary health care design, pp. 42

Steemers K. (2015), "Architecture for well-being and health", Daylight \& Architecture, Spring 2015, Issue 23, pp 6-27.

Turner, A., Doxa, M., O'Sullivan, D., and Penn, A. (2001) From Isovists to Visibility Graphs: A Methodology for the Analysis of Architectural Space. Environment and Planning B: vol 28, 103121. pp.108-109

Ulrich R. (2001), "Effects of healthcare environmental design on medical outcomes", in: Dilani A. (ed.), Design and Health - The therapeutic benefits of design, Stockholm: AB Svensk Byggtjanst

WHO (2019), Primary health care in Kosova: rapid assessment

WHO and UNICEF. (2018). A vision for primary health care in the 21st century: towards universal health coverage and the Sustainable Development Goals. 